of raised intracranial pressure-surely an unwarranted measure. There is certainly no necessity for the injection of $75 \mathrm{ccs}$. of air, or oxygen, in the majority of cases, particularly if the cisternal route is applicable. Electro-encephalography has gained acceptance as of definite value, and would justify additional reference, particularly in view of the lack of risk attendant on its use.

Mr. Rowbotham's experiences of extra-dural haemorrhage are exceptional. Apart from these one receives the impression that the demands for surgical intervention are greater than is actually the case. Statistics are offered in support of "active" care as against conservative treatment without qualifying their screening influence-to say that 3o per cent more fatalities arose out of the latter could be taken to infer either that thirty additional deaths took place, or alternatively that whereas with active measures three cases proved fatal, in cases treated conservatively a fatal termination ensued in four patients.

Operative interventions and the associated technique are well described, and well designed. Every effort has been made to explain those small technical details which can make a neuro-surgical operation a major success.

References to prognosis are not consistent, e.g. while two years is cited as the minimum period for gauging the full, available recovery, it is suggested that compensation procedures should not extend beyond six months. There is, however, an interesting and valuable discussion on such problems as prognosis and psychological states.

The publication as a whole is excellent and meets a long-felt need. Never was the time more opportune for the appearance of what must prove to be a valued contribution to the literature.

\section{ANAESTHETICS AFLOAT}

By Surg.-Lieut.-Cdr. R. WoolmeR, R.N.V.R. Messrs. H. K. Lewis, London. 1942. Price 6s.

Anaesthetics Afloat, written by an author who is an anaesthetist of no mean standing, will be welcomed by the medical officers in the Royal Navy.

It deals with all the usual types of anaesthetics that are required for casualties that are likely to be met with during normal service and naval action.

His description of how to use open ether is excellent. The chapter on spinal anaesthesia leaves little to be desired, and he wisely describes intravenous anaesthesia as a specialist's job, but one feels that this could have been enlarged upon as he refers to it in most of his chapters as a means of giving an anaesthetic to relieve pain, especially where the casualty was in an awkward position and had to be removed in difficult circumstances.

The book gives the practising anaesthetist definite help and a means of improving his technique, still more does it assist the naval doctor who has to administer an anaesthetic with limited experience, and enable him to give the various types of anaesthetics that are required for severe cases caused during naval action.

The main point is, that it should stimulate the average naval doctor to improve his knowledge in this all-important subject, and should be the means of making him attempt to get further information and practice in case of future requirements.

\section{BROMPTON HOSPITAL REPORTS} Vol. xi. 1942

Gale and Polden, Aldershot. 1943. Price $5 \mathrm{~s}$.

This small volume contains a wealth of reading, not only of interest to the chest physician, but also to the general practitioner. The article by $\mathrm{Dr}$ Clifford Hoyle on "The Care of the Dying" is indeed a masterpiece of human understanding and therapeutics. Furthermore, the literary style is such that one reads the article with ease and enjoyment.

Of the other articles, Mr. Price-Thomas's "Persistence and Closure of Pulmonary Cavities" is extremely instructive, and sheds much light upon the efficient treatment of these.

The inclusion of a report by the Lady Almoner, Miss Marx, in which she discusses the follow-up work at the Brompton Hospital, shows not only the appreciation in which she is held by the medical staff, but also the valuable work which she has done.

The chest physician will be particularly interested in "The Anatomy" of the Bronchial Tree" by Dr. Foster-Carter, which should greatly help him to understand more about the lungs and bronchi.

The illustrations are, for the most part, very well reproduced, the exception being Fig. III on Plate 2.

This little book is therefore commended.

\section{THE EAR, NOSE AND THROAT IN THE SERVICES}

By R. Scott Stevenson. Oxford University Press. London. I943. Price 5s.

This book, as stated in the Preface, is intended for Medical Officers in the Services not practising in this speciality. It is a small book, yet covers the whole field, so of necessity it deals briefly with the subject, being at times, somewhat dogmatic. Its size and brevity are, however, an advantage to the General Duties Officer, and those who have had no special ear, nose and throat experience should find it most helpful.

\section{DISEASES OF THE NERVOUS SYSTEM}

By F. M. R. Walshe. 3rd Edition. E. \& S. Livingstone, Edinburgh. 1943. Price I5s.

The merits of a book of this character can be gauged by its popularity, and the call for three editions in three years shows how successful Dr. Walshe has been in making neurology intelligible to students within the compass of some 300 pages.

Dr. Walshe has wisely resisted the tendency to embody more new material in successive editions till they fail in their original purpose. The space devoted to topical subjects is likely to be proportional to the interests of the members of the current examining bodies.

A note on how to avoid false high readings of cerebro-spinal fluid pressure might be of value, and many workers now prefer 50 per cent sucrose to 50 per cent glucose for the reduction of intracranial pressure.

Some may doubt the wisdom of dethroning syphilis from its position of eminence under present world conditions, and claim for it at least a mention under the heading of Symptomatic Epilepsy. It is, however, the personal and dogmatic presentation of the subject which makes for clarity, as do the 46 line diagrams and illustrations, while Messrs. Livingstone are to be congratulated on the printing, format, and price. 